\title{
Review Article \\ Newer Root Canal Irrigants in Horizon: A Review
}

\author{
Sushma Jaju ${ }^{1}$ and Prashant P. Jaju ${ }^{2}$ \\ ${ }^{1}$ Dentocare Multispeciality Dental Clinic, 20 Pratik Arcade near Dena Bank, Bytco Point Nashik Road, Nashik, \\ Maharashtra 422101, India \\ ${ }^{2}$ Department of Oral Medicine, Diagnosis and Radiology, MGV's KBH Dental College \& Hospital, Nashik, Maharashtra, India
}

Correspondence should be addressed to Prashant P. Jaju, docprashant_jaju@yahoo.com

Received 13 July 2011; Revised 25 September 2011; Accepted 11 October 2011

Academic Editor: Ahmad Waseem

Copyright () 2011 S. Jaju and P. P. Jaju. This is an open access article distributed under the Creative Commons Attribution License, which permits unrestricted use, distribution, and reproduction in any medium, provided the original work is properly cited.

Sodium hypochloride is the most commonly used endodontic irrigant, despite limitations. None of the presently available root canal irrigants satisfy the requirements of ideal root canal irrigant. Newer root canal irrigants are studied for potential replacement of sodium hypochloride. This article reviews the potential irrigants with their advantages and limitations with their future in endodontic irrigation.

\section{Introduction}

The effectiveness of endodontic files, rotary instrumentation, irrigating solutions, and chelating agents to clean, shape, and disinfect root canals underpins the success, longevity, and reliability of modern endodontic treatments. The role of microorganisms in the development and perpetuation of pulp and periapical diseases has clearly been demonstrated in animal models and human studies [1-4].

Elimination of microorganisms from infected root canals is a complicated task. The chances of a favourable outcome with root canal treatment are significantly higher if infection is eradicated effectively before the root canal system is obturated. However, if microorganisms persist at the time of obturation, or if they penetrate into the canal after obturation, there is a high risk of treatment failure $[5,6]$.

Numerous measures have been described to reduce the number of microorganisms in the root canal system, including the use of various instrumentation techniques, irrigation regimens, and intracanal medicaments. The use of chemical agents during instrumentation to completely clean all aspects of the root canal system is central to successful endodontic treatment [7]. Irrigation is complementary to instrumentation in facilitating the removal of pulp tissue and/or microorganisms [8]. Irrigation dynamics plays an important role $[9,10]$; the effectiveness of irrigation depends on the working mechanism(s) of the irrigant and the ability to bring the irrigant in contact with the microorganisms and tissue debris in the root canal $[11,12]$.

The root canal system is complex and accessory features, such as fins, cul de sacs, and intercanal communications, are colonized by microorganisms once the tooth becomes infected $[13,14]$. Self-aggregates of monobacterial morphotypes and coaggregates of different bacterial morphotypes are also found adhering to teeth. The interbacterial spaces are occupied by an amorphous material, spirochetes, and hyphal-like structures that are suggestive of fungi $[15,16]$. Costerton et al. used the term "biofilm" to describe this clustering of bacteria [17]. Bacteria within a biofilm have increased resistance to a variety of external hostile influences, such as the host defense responses, antibiotics, antiseptics, and shear forces, compared with isolated bacterial cells [18]. This article reviews recent developments in the identification of new agents to sterilize infected root canal.

\section{Root Canal Bacterium}

Primary root canal infections are polymicrobial, typically dominated by obligatory anaerobic bacteria [19]. The most frequently isolated microorganisms before root canal treatment include Gram-negative anaerobic rods, Gram-positive anaerobic cocci, Gram-positive anaerobic and facultative rods, Lactobacillus species, and Gram-positive facultative Streptococcus species [20]. The obligate anaerobes are rather 
easily eradicated during root canal treatment. On the other hand, facultative bacteria such as nonmutans Streptococci, Enterococci, and Lactobacilli, once established, are more likely to survive chemomechanical instrumentation and root canal medication [21]. In particular Enterococcus faecalis has gained attention in the endodontic literature, as it can frequently be isolated from root canals in cases of failed root canal treatments $[22,23]$. In addition, yeasts may also be found in root canals associated with therapy-resistant apical periodontitis [24].

\section{Root Canal Irrigants}

It is generally believed that mechanical enlargement of canals must be accompanied by copious irrigation in order to facilitate maximum removal of microorganisms so that the prepared canal becomes as bacteria-free as possible [25, 26]. Ideally an irrigant should provide a mechanical flushing action, be microbiocidal and dissolve remnants of organic tissues without damaging the periradicular tissues if extruded into the periodontium. In addition, the root canal irrigants should be biocompatible with oral tissues. A large number of substances have been used as root canal irrigants, including acids (citric and phosphoric), chelating agent (ethylene diaminetetraacetic acid EDTA), proteolytic enzymes, alkaline solutions (sodium hypochlorite, sodium hydroxide, urea, and potassium hydroxide), oxidative agents (hydrogen peroxide and Gly-Oxide), local anesthetic solutions, and normal saline [27].

The most widely used endodontic irrigant is $0.5 \%$ to $6.0 \%$ sodium hypochlorite $(\mathrm{NaOCl})$, because of its bactericidal activity and ability to dissolve vital and necrotic organic tissue $[28,29]$. However, $\mathrm{NaOCl}$ solutions exert no effects on inorganic components of smear layer. Chelant and acid solutions have been recommended for removing the smear layer from instrumented root canals, including ethylene diaminetetraacetic acid (EDTA), citric acid, and phosphoric acid $[30,31]$.

Ideal Requirement of Root Canal Irrigants. It appears evident that root canal irrigants ideally should [20]

(i) have a broad antimicrobial spectrum and high efficacy against anaerobic and facultative microorganisms organized in biofilms,

(ii) dissolve necrotic pulp tissue remnants,

(iii) inactivate endotoxin,

(iv) prevent the formation of a smear layer during instrumentation or dissolve the latter once it has formed,

(v) be systemically nontoxic,

(vi) be non caustic to periodontal tissues,

(vii) be little potential to cause an anaphylactic reaction.

3.1. Sodium Hypochlorite. Chlorine is one of the most widely distributed elements on earth. It is not found in a free state in nature, but it exists in combination with sodium, potassium, calcium, and magnesium. In the human body, chlorine compounds are part of the nonspecific immune defense. They are generated by neutrophils via the myeloperoxidasemediated chlorination of a nitrogenous compound or set of compounds [20].

Hypochlorite preparations are sporicidal and virucidal and show far greater tissue dissolving effects on necrotic than on vital tissues. These features prompted the use of aqueous sodium hypochlorite in endodontics as the main irrigant as early as 1920 .

There has been much controversy over the concentration of hypochlorite solutions to be used in endodontics. The antibacterial effectiveness and tissue dissolution capacity of aqueous hypochlorite is a function of its concentration, and so is its toxicity [20]. It appears that the majority of American practitioners use "full strength" $5.25 \%$ sodium hypochlorite as it is sold in the form of household bleach leading to several adverse reactions like irritation and decrease in flexural strength of dentin. Also decrease in microbiota was also not significantly altered with this high concentration. It must be realized that during irrigation, fresh hypochlorite consistently reaches the canal system, and concentration of the solution may thus not play a decisive role [20]. Unclean areas may be a result of the inability of solutions to physically reach these areas rather than their concentration. Hence, based on the currently available evidence, there is no rationale for using hypochlorite solutions at concentrations over $1 \% \mathrm{wt} / \mathrm{vol}$. One of the methods to improve the efficacy of sodium hypochlorite was to use heated solution. This improves their immediate tissue-dissolution capacity. Furthermore, heated hypochlorite solutions remove organic debris from dentin shavings more efficiently than unheated counterparts [6]. However, there are no clinical studies available at this point to support the use of heated sodium hypochlorite. Ultrasonic activation of sodium hypochlorite has also been advocated, as this would "accelerate chemical reactions, create cavitational effects, and achieve a superior cleansing action" [20]. However, results obtained with ultrasonically activated hypochlorite versus irrigation alone are contradictory, in terms of both root canal cleanliness and remaining microbiota in the infected root canal system after the cleaning and shaping procedure. it should also be noted that time is a factor that has gained little attention in endodontic studies. Even fast-acting biocides such as sodium hypochlorite require an adequate working time to reach their potential [20]. This should especially be considered in view of the fact that rotary root canal preparation techniques have expedited the shaping process [20]. The optimal time that a hypochlorite irrigant at a given concentration needs to remain in the canal system is an issue yet to be resolved.

3.2. EDTA. Although sodium hypochlorite appears to be the most desirable single endodontic irrigant, it cannot dissolve inorganic dentin particles and thus prevent the formation of a smear layer during instrumentation [30]. Demineralizing agents such as ethylenediamine tetraacetic acid (EDTA) and citric acid have therefore been recommended as adjuvants in root canal therapy $[30,31]$. 
These are highly biocompatible and are commonly used in personal care products. Although citric acid appears to be slightly more potent at similar concentration than EDTA, both agents show high efficiency in removing the smear layer [20]. In addition to their cleaning ability, chelators may detach biofilms adhering to root canal walls. An alternating irrigating regimen of $\mathrm{NaOCl}$ and EDTA may be more efficient in reducing bacterial loads in root canal systems than $\mathrm{NaOCl}$ alone [20]. Antiseptics such as quaternary ammonium compounds (EDTAC) or tetracycline antibiotics (MTAD) have been added to EDTA and citric acid irrigants, respectively, to increase their antimicrobial capacity. The clinical value of this, however, is questionable [32, 33]. Generally speaking, the use of antibiotics instead of biocides such as hypochlorite or chlorhexidine appears unwarranted, as the former were developed for systemic use rather than local wound debridement and have a far narrower spectrum than the latter. Both citric acid and EDTA immediately reduce the available chlorine in solution, rendering the sodium hypochlorite irrigant ineffective on bacteria and necrotic tissue. Hence, citric acid or EDTA should never be mixed with sodium hypochlorite [20].

Calt and Serper demonstrated that $10 \mathrm{~mL}$ irrigation with $17 \%$ EDTA for 1 minute was effective in removal of smear layer, but a 10-minute application caused excessive peritubular and intertubular dentinal erosion. Increasing contact time and concentration of EDTA from $10 \%$ to $17 \%$ as well as a $\mathrm{pH}$ of 7.5 versus $\mathrm{pH} 9.0$ has been shown to increase dentin demineralization.

3.3. Chlorhexidine. Chlorhexidine was developed in the late 1940s in the research laboratories of Imperial Chemical Industries Ltd. (Macclesfield, England). The original salts were chlorhexidine acetate and hydrochloride, both of which are relatively poorly soluble in water [20]. Hence, they have been replaced by chlorhexidine digluconate. Chlorhexidine is a potent antiseptic, which is widely used for chemical plaque control in the oral cavity. Aqueous solutions of 0.1 to $0.2 \%$ are recommended for that purpose, while $2 \%$ is the concentration of root canal irrigating solutions usually found in the endodontic literature [20]. It is commonly held that chlorhexidine would be less caustic than sodium hypochlorite. However, that is not necessarily the case [20]. A $2 \%$ chlorhexidine solution is irritating to the skin [20]. As with sodium hypochlorite, heating a chlorhexidine irrigant of lesser concentration could increase its local efficacy in the root canal system while keeping the systemic toxicity low. Despite its usefulness as a final irrigant, chlorhexidine cannot be advocated as the main irrigant in standard endodontic cases, because (a) chlorhexidine is unable to dissolve necrotic tissue remnants, and (b) chlorhexidine is less effective on Gram-negative than on Gram-positive bacteria.

\section{Need for Newer Root Canal Irrigants}

All the irrigation solutions at our disposable have their share of limitations and the search for an ideal root canal irrigant continues with the development of newer materials and methods. Newer root canal irrigants in the horizon are as follows:
(1) MTAD,
(2) tetraclean,
(3) electrochemically activated solutions,
(4) ozonated water,
(5) photon-activated disinfection,
(6) herbal irrigants.

The article reviews the advantages and shortcomings of these newer irrigating agents and their potential role in endodontic irrigation in near future.

4.1. MTAD. Bio Pure MTAD (Dentsply, Tulsa, OK) is a mixture of a tetracycline isomer, an acetic acid, and Tween 80 detergent (MTAD) - was designed to be used as a final root canal rinse before obturation [32].

Tetracycline has many unique properties of low $\mathrm{pH}$ and thus can act as a calcium chelator and cause enamel and root surface demineralization [34]. Its surface demineralization of dentin is comparable to that seen using citric acid [35]. In addition, it has been shown that it is a substantive medication (becomes absorbed and gradually released from tooth structures such as dentin and cementum $[33,35]$. Finally, studies have shown that tetracycline significantly enhances healing after surgical periodontal therapy. Manufacturer instructions for using this irrigant were flooding the root canal with $1 \mathrm{~mL}$ of the irrigant and soaking for 5 minutes, and the remaining $4 \mathrm{~mL}$ is then delivered with continuous irrigation and suction [32].

MTAD has some advantages over conventional irrigants and solutions used in root canal treatment. MTAD is effective in removing the smear layer along the whole length of the root canal and in removing organic and inorganic debris and does produce any signs of erosion or physical changes in dentine, whereas a mixture of $5.25 \%$ sodium hypochlorite and 17\% EDTA does [36-38]. In particular, MTAD mixture is effective against $E$. faecalis, and it is also less cytotoxic than a range of endodontic medicaments, including eugenol, hydrogen peroxide (3\%), EDTA, and calcium hydroxide paste [39-42].

Torabinejad et al. showed that the effectiveness of the MTAD was enhanced when low concentration of $\mathrm{NaOCl}$ is used as an intracanal irrigant before the use of MTAD as a final rinse. MTAD does not seem to significantly change the structure of the dentinal tubules [32].

Newberry et al. determined the antimicrobial effect of MTAD as a final irrigant on eight strains of Enterococcus faecalis. After irrigating with $1.3 \% \mathrm{NaOCl}$, the root canal and the external surfaces were exposed to MTAD for 5 minutes. Roots or dentin shavings were cultured to determine the growth of E. faecalis. The results showed that this treatment regimen was effective in completely eliminating growth in seven of eight strains of E. faecalis [43]. Mancini et al. compared the efficacy of Bio- Pure MTAD, 17\% EDTA, and $42 \%$ citric acid in endodontic smear layer removal and degree of erosion in the apical third of endodontic canals 
[44]. None of the agents were found to be efficient in the apical one third of the root canal. This finding is in contrast with the results of Torabinejad et al. showing an effective cleaning action with BioPure MTAD in the apical third $[32,36]$. The placement of MTAD with a cotton-wrapped barbed broach allows intimate contact of the solution even in the apical region of the canals and improves debridement of the entire root canal wall according to Torabinejad et al. [32].

The effectiveness of sodium hypochlorite, chlorhexidine gluconate, and chlorhexidine acetate on C. albicans is documented in the literature $[45,46]$. Sen et al. found that EDTA was the most effective irrigant against $C$. albicans using the agar diffusion test [47]. Doxycycline is primarily a bacteriostatic antibiotic and inhibits bacterial protein synthesis by binding to the $30 \mathrm{~S}$ bacterial ribosome. Doxycycline is active against a wide range of gram-positive and gram-negative organisms, but it is not active against fungi [48]. As with other antibiotic preparations, use of this drug results in changes in the balance of normal flora and overgrowth of nonsusceptible organisms, including fungi. Citric acid has antibacterial properties but no effect against C. Albicans [49]. It follows that antifungal efficacy of MTAD when used in combination with $\mathrm{NaOCl}$ may be clinically insignificant. To further improve antisepsis, an additional rinse with chlorhexidine after irrigation with $\mathrm{NaOCl}$ may be of benefit [50].

Ruff et al. showed that $6 \% \mathrm{NaOCl}$ and $2 \%$ chlorohexidine were equally effective and statistically significantly superior to BioPure MTAD and 17\% EDTA in antifungal activity [51]. Clegg et al. questioned the ability of MTAD to remove or disrupt bacterial biofilms in root canals $[29,42]$. MTAD is less cytotoxic than eugenol, $3 \%$ hydrogen peroxide, calcium hydroxide paste, $5.25 \% \mathrm{NaOCl}$, Peridex, and EDTA and more cytotoxic than $2.63 \%, 1.31 \%$, and $0.66 \% \mathrm{NaOCl}$.

MTAD can be a useful irrigant due to its antimicrobial property, less cytotoxic, but its effectiveness against fungi and value in the apical one third need to be assessed further.

4.2. Tetraclean. Tetraclean (Ogna Laboratori Farmaceutici, Muggiò (Mi), Italy), like MTAD, is a mixture of an antibiotic, an acid, and a detergent. However, the concentration of the antibiotic, doxycycline $(50 \mathrm{mg} / \mathrm{mL})$, and the type of detergent (polypropylene glycol) differ from those of MTAD [52].

Giardino et al. compared the surface tension of $17 \%$ EDTA, Cetrexidin, Smear Clear, 5.25\% NaOCl, MTAD and Tetraclean [52]. The $\mathrm{NaOCl}$ and EDTA had the highest surface tension, whereas Cetrexedin and Tetraclean had the lowest values.

In another study, they compared the antimicrobial efficacy of $5.25 \% \mathrm{NaOCl}, \mathrm{MTAD}$, and Tetraclean against an E. faecalis biofilm generated on cellulose nitrate membrane filters.

Only the $\mathrm{NaOCl}$ could disaggregate and remove the biofilm at every time interval tested although treatment with Tetraclean caused a high degree of biofilm disaggregation at each time interval when compared with MTAD [53].
4.3. Electrochemically Activated Solutions. Electrochemically Activated (ECA) solutions are produced from tap water and low-concentrated salt solutions [54-56].

The ECA technology represents a new scientific paradigm developed by Russian scientists at the All-Russian Institute for Medical Engineering (Moscow, Russia, CIS). Principle of ECA is transferring liquids into a metastable state via an electrochemical unipolar (anode or cathode) action through the use of an element/reactor ("Flow-through Electrolytic Module" or FEM). The FEM consists of an anode, a solid titanium cylinder with a special coating that fits coaxially inside the cathode, a hollow cylinder also made from titanium with another special coating. A ceramic membrane separates the electrodes. The FEM is capable of producing types of solutions that have bactericidal and sporicidal activity; yet they are odourless, safe to human tissue, and essentially noncorrosive for most metal surfaces [54].

Electrochemical treatment in the anode and cathode chambers results in the synthesis of two types of solutions: that produced in the anode chamber is termed an Anolyte, and that produced in the cathode chamber is Catholyte. Anolyte solutions containing a mixture of oxidizing substances demonstrate pronounced microbiocidal effectiveness against bacteria, viruses, fungi, and protozoa [54, 57].

Anolyte solution has been termed Superoxidized Water or Oxidative Potential Water [58,59]. Depending on the type ECA device that incorporated the FEM elements the $\mathrm{pH}$ of anolyte varies; it may be acidic (anolyte), neutral (anolyte neutral), or alkaline (anolyte neutral cathodic); acidic anolyte was used initially but in recent years the neutral and alkaline solutions have been recommended for clinical application. Under clean conditions, freshly generated superoxidized solution was found to be highly active against all these microorganisms giving a $99.999 \%$ or greater reduction in two minutes or less. That allowed investigators to treat it as a potent microbiocidal agent $[58,60]$.

It is nontoxic when being in contact with vital biological tissues $[61,62]$.

Clinical applications of anolyte and catholyte were reported to be effective [63]. ECA solutions demonstrated more pronounced clinical effect and were associated with fewer incidences of allergic reactions compared to other antibacterial irrigants tested [63]. Cleaning efficiency and safety for surfaces of dental instruments and equipment has been demonstrated in a number of studies.

The experience of oxidative potential water application for irrigation of root canals has been reported [59]. However, Haga and coworkers studied the effect of acidic anolyte solutions. The anolyte neutral cathodic solution (ANC) provides an increased antiseptic effect and an enhanced cleaning ability at lower concentrations of active chlorine compared to the acidic anolyte and anolyte neutral solutions because of its higher concentration of peroxides. Both electrolyzed neutral water and oxidative potential water are claimed to be harmless to humans and are probably similar to ECA water $[33,37,54]$.

The quality of debridement was better in the coronal and middle parts of canal walls where only scattered debris was noted in contrast to the apical part that contained numerous 
debris. This observation confirms the previously published results [64].

According to Solovyeva and Dummer $\mathrm{NaOCl}$ and ECA solutions left a thinner smear layer with a smoother and more even surface [54]. The texture of the canal surfaces treated with ECA solutions was relatively uniform in the various regions of the root canal and did not seem to be influenced by the method of instrumentation, that is, manually or mechanical. Irrigation with $\mathrm{NaOCl}$ or ECA solutions enhanced the opening of dentine tubules. It is important to note that irrigation with $\mathrm{NaOCL}$ resulted in open tubules predominantly in the coronal and middle thirds of root canals with no signs of tubule orifices were revealed in the apical third of canals. Irrigating with anolyte neutral cathodic as well as with alternate ANC and catholyte resulted in more numerous open dentine tubules in the apical as well as in the coronal regions. Solovyeva and Dummer studied the cleaning effectiveness of root canal irrigation with ECA solution and found that it was similar to $\mathrm{NaOCl}$ in debris removal but was more effective than $\mathrm{NaOCl}$ in smear layer removal [54].

ECA is showing promising results due to ease of removal of debris and smear layer, nontoxic and efficient in apical one third of canal. It has a potential to be an efficient root canal irrigant.

4.4. Ozonated Water. Ozone is a chemical compound consisting of three oxygen atoms $\left(\mathrm{O}_{3}\right.$-triatomic oxygen $)$, a higher energetic form than normal atmospheric oxygen $\left(\mathrm{O}_{2}\right)$. Thus, the molecules of these two forms are different in structure. Ozone is produced naturally by the following natural methods.

(i) The first is from electrical discharges following thunderstorms. Ozone is created when an oxygen molecule receives an electrical discharge breaking it into two oxygen atoms. The individual atoms combine with another oxygen molecule to form an $\mathrm{O}_{3}$ molecule.

(ii) The second from ultraviolet rays emitted from the sun which plays the role of electrical discharge over oxygen present in the stratosphere, thus, creating the ozone layer which absorbs most of the ultraviolet radiation emitted by the sun.

Ozone is a very powerful bactericide that can kill microorganisms effectively. It is an unstable gas, capable of oxidizing any biological entity. It was reported that ozone at low concentration, $0.1 \mathrm{ppm}$, is sufficient to inactivate bacterial cells including their spores [65]. It is present naturally in air and can be easily produced by ozone generator. When introduced in water, ozone dissolves rapidly and dissociates rather quickly. The concentration of ozone in ozonated water can be measured using a dissolved ozone meter. Although ozonated water is a powerful antimicrobial agent against bacteria, fungi, protozoa, and viruses, less attention has been paid to the antibacterial activity of ozonated water in bacterial biofilm and hence in root canal infection $[66,67]$.
Cavitation is the formation of vapor-containing bubbles inside a fluid causing formation of pressure waves/ shockwaves characterized by rapid changes in pressure and high amplitude [68]. A forced collapse of bubbles causes implosions that impact on surfaces, causing shear forces, surface deformation, and removal of surface material [69]. In the root canal environment, such shockwaves could potentially disrupt bacterial biofilms, rupture bacterial cell walls, and remove smear layer and debris. Shockwave generation can also enhance the breakdown of agents such as hydrogen peroxide and ozone dissolved in water and thereby enhance their disinfecting and debriding actions [70, 71].

Nagayoshi et al. found that killing ability of ozonated water and $2.5 \%$ of sodium hypochlorite was almost comparable when the specimen was irrigated with sonication [72].

Study by Hems et al. however found that $\mathrm{NaOCI}$ was superior to ozonated water in killing E. faecalis in broth culture and in biofilm [73]. Ibrahim and Abdullah studied that $1.31 \% \mathrm{NaOCI}$ might allow passage of oxidation of ozonated water, thus increasing their antibacterial effect compared to $1.31 \% \mathrm{NaOCI}$ or ozonated water alone [67].

Cardoso evaluated the efficiency of ozonated water as an irrigating agent during endodontic treatment in an attempt to eliminate Candida albicans and Enterococcus faecalis and toneutralize lipopolysacharides (LPSs) inoculated in root canals [16]. It was possible to see effective antimicrobial action after ten minutes of water ozonization on the microbial suspension. There was no residue found when a second sample was collected seven days later. However, ozonated water was not able to neutralize E. coli and LPS inside root canals and the remaining amount of LPS may have biological consequences such as apical periodontitis. Estrela et al. assessed the antimicrobial efficiency of aqueous ozone, gaseous ozone, $2.5 \%$ sodium hypoclorite, and $2 \%$ chlorexidine in human root canals infected with Enterococcus faecalis. None of the solutions tested were found to be effective against the bacterial suspension $[74,75]$.

There is need for further studies and modifications in ozonated water before it could be used as a root canal irrigant.

4.5. Photon-Activated Disinfection. The use of photodynamic therapy (PDT) for the inactivation of microorganisms was first shown by Oscar Raab who reported the lethal effect of acridine hydrochloride on Paramecia caudatum [76]. PDT is based on the concept that nontoxic photosensitizers can be preferentially localized in certain tissues and subsequently activated by light of the appropriate wavelength to generate singlet oxygen and free radicals that are cytotoxic to cells of the target tissue [77]. Methylene blue (MB) is a wellestablished photosensitizer that has been used in PDT for targeting various gram-positive and gram-negative oral bacteria and was previously used to study the effect of PDT on endodontic disinfection [78-85]. Several studies have shown incomplete destruction of oral biofilms using MB-mediated PDT due to reduced penetration of the photosensitizer [8689]. Soukos et al. used the combined effect of MB and red 
light $(665 \mathrm{~nm})$ exhibited up to $97 \%$ reduction of bacterial viability [79]. The results suggested the potential of PDT to be used as an adjunctive antimicrobial procedure after standard endodontic chemomechanical debridement, but they also demonstrated the importance of further optimization of light dosimetry for bacterial photodestruction in root canals. Along with methylene blue, tolonium chloride has been also used as a photosensitizing agent. It is applied to the infected area and left in situ for a short period. The agent binds to the cellular membrane of bacteria, which will then rupture when activated by a laser source emitting radiation at an appropriate wavelength (e.g., $635 \mathrm{~nm}$ radiation emitted by SaveDent; Denfotex Light Systems Ltd., Inverkeithing, United Kingdom). The light is transmitted into the root canals at the tip of a small flexible optical fiber that is attached to a disposable handpiece. The laser emits a maximum of only $100 \mathrm{~mW}$ and does not generate sufficient heat to harm adjacent tissues. Furthermore, tolonium chloride dye is biocompatible and does not stain dental tissue. The data quoted by the manufacturer suggest that this PAD system has antimicrobial efficacy [90]. Lethal photosensitization of Streptococcus intermedius biofilms in root canals is unable to achieve a total kill rate when a combination of a helium-neon laser and tolonium chloride is used [91].

Leticia et al. investigated the antibacterial effects of photodynamic therapy (PDT) with methylene blue (MB) or toluidine blue (TB) (both at $15 \mathrm{mg} / \mathrm{mL}$ ) as a supplement to instrumentation/irrigation of root canals experimentally contaminated with Enterococcus faecalis [92]. The study revealed that $\mathrm{PDT}$ with either $\mathrm{MB}$ or $\mathrm{TB}$ may not exert a significant supplemental effect to instrumentation/irrigation procedures with regard to intracanal disinfection, until further adjustments in the PDT protocol are modified before clinical use is recommended.

In contrast, irrigation with sodium hypochlorite (3\%) eliminated the entire bacterial population. The difference could be because the optical fiber was not properly introduced into the root canals, and so the light could not transmit through the tooth structure. Thus, PAD might not be able to achieve a $100 \%$ kill rate in infected root canals that have complex anatomic features and colonized by polymicrobial biofilms of varying properties.

Pagonis et al. studied the in vitro effects of poly(lacticcoglycolic acid) (PLGA) nanoparticles loaded with the photosensitizer methylene blue $(\mathrm{MB})$ and light against Enterococcus faecalis (ATCC 29212) [93]. The study showed that utilization of PLGA nanoparticles encapsulated with photoactive drugs may be a promising adjunct in antimicrobial endodontic treatment.

PAD can currently be considered a useful adjunct to conventional root canal treatment.

4.6. Herbal. Murray et al. evaluated Morinda citrifolia juice in conjunction with EDTA as a possible alternative to NaOCl. Triphala (IMPCOPS Ltd, Chennai, India) is an Indian ayurvedic herbal formulation consisting of dried and powdered fruits of three medicinal plants, Terminalia bellerica, Terminalia chebula, and Emblica officinalis, and green tea polyphenols (GTPs; Essence and Flavours, Mysore, India); the traditional drink of Japan and China is prepared from the young shoots of tea plant Camellia sinensis [94-97].

Dimethyl sulfoxide (DMSO) is used as a solvent for Triphala and GTP, although they are readily soluble in water. DMSO is a clean, safe, highly polar, aprotic solvent that helps in bringing out the pure properties of all the components of the herb being dissolved [98, 99].

Herbal alternatives showed promising antibacterial efficacy on 3- and 6-week biofilm along with MTAD and 5\% sodium hypochlorite [97].

Although Triphala and green tea polyphenols (GTPs) exhibited similar antibacterial sensitivity on E. faecalis planktonic cells, Triphala showed more potency on E. faecalis biofilm. This may be attributed to its formulation, which contains three different medicinal plants in equal proportions. In such formulations, different compounds may be of help in enhancing the potency of the active compounds resulting in an additive or synergistic positive effect. According to Prabhakar et al. 5\% of sodium hypochlorite exhibited excellent antibacterial activity in both 3-week and 6-week biofilm, whereas Triphala and MTAD showed complete eradication only in 3-week biofilm [97].

Triphala and GTPs are proven to be safe, containing active constituents that have beneficial physiologic effect apart from its curative property such as antioxidant, antiinflammatory, and radical scavenging activity and may have an added advantage over the traditional root canal irrigants [100-103].

\section{Conclusion}

The article reviewed the potential new irrigants that could substitute the traditional endodontic irrigants. Available literature and studies demonstrate advantages and limitations of each irrigant under consideration and none of them satisfy the requirements of the ideal root canal irrigant completely. Presently these newer irrigants could be used as an adjunct to $\mathrm{NaOCl}$, with the hunt for the elusive ideal root canal irrigant continues.

\section{Conflict of Interests}

The authors deny any conflict of interests.

\section{References}

[1] S. Kakehashi, H. R. Stanley, and R. J. Fitzgerald, "The effects of surgical exposure of dental pulps in germ-free and conventional laboratory rats," Oral Surgery, Oral Medicine, Oral Pathology, vol. 20, no. 3, pp. 340-348, 1965.

[2] A. J. Moller, L. Fabricius, and G. Dahlen, "Influence on periapical tissues of indigenous oral bacteria and necrotic pulp tissue in monkeys," Scandinavian Journal of Dental Research, vol. 89, no. 6, pp. 475-484, 1981.

[3] G. Sundqvist, "Ecology of the root canal flora," Journal of Endodontics, vol. 18, no. 9, pp. 427-430, 1992.

[4] Z. Mohammadi, "An update on the antibiotic-based root canal irrigation solutions," Iranian Endodontic Journal, vol. 3, pp. 1-7, 2008. 
[5] U. Sjogren, D. Figdor, S. Persson, and G. Sundqvist, "Influence of infection at the time of root filling on the outcome of endodontic treatment of teeth with apical periodontitis," International Endodontic Journal, vol. 30, no. 5, pp. 297-306, 1997.

[6] I. El karim, J. Kennedy, and D. Hussey, "The antimicrobial effects of root canal irrigation and medication," Oral Surgery, Oral Medicine, Oral Pathology, Oral Radiology and Endodontology, vol. 103, no. 4, pp. 560-569, 2007.

[7] Y. Shen, S. Stojicic, W. Qian, I. Olsen, and M. Haapasalo, "The synergistic antimicrobial effect by mechanical agitation and two chlorhexidine preparations on biofilm bacteria," Journal of Endodontics, vol. 36, no. 1, pp. 100-104, 2010.

[8] M. Haapasalo, U. Endal, H Zandi et al., "Eradication of endodontic infection by instrumentation and irrigation solutions," Endodontic Topics, vol. 10, pp. 77-102, 2005.

[9] K. Gulabivala, B. Patel, G. Evans et al., "Effects of mechanical and chemical procedures on root canal surfaces," Endodontic Topics, vol. 10, pp. 103-122, 2005.

[10] L. S. Gu, J. R. Kim, J. Ling, K. K. Choi, D. H. Pashley, and F. R. Tay, "Review of contemporary irrigant agitation techniques and device," Journal of Endodontics, vol. 35, no. 6, pp. 791804, 2009.

[11] A. D. Walmsley, "Ultrasound and root canal treatment: the need for scientific evaluation," International Endodontic Journal, vol. 20, no. 3, pp. 105-111, 1987.

[12] L. W. M. van der Sluis, M. Versluis, M. K. Wu, and P. R. Wesselink, "Passive ultrasonic irrigation of the root canal: a review of the literature," International Endodontic Journal, vol. 40, no. 6, pp. 415-426, 2007.

[13] F. J. Vertucci, "Root canal anatomy of the human permanent teeth," Oral Surgery Oral Medicine and Oral Pathology, vol. 58, no. 5, pp. 589-599, 1984.

[14] A. M. Alavi, A. Opasanon, Y. L. Ng, and K. Gulabivala, "Root and canal morphology of Thai maxillary molars," International Endodontic Journal, vol. 35, no. 5, pp. 478-485, 2002.

[15] P. N. Nair, "Light and electron microscopic studies of root canal flora and periapical lesions," Journal of Endodontics, vol. 13, no. 1, pp. 29-39, 1987.

[16] R. P.-Y. Ng, "Sterilization in root canal treatment: current advances," Hong Kong Dental Journal, vol. 1, pp. 52-57, 2004.

[17] J. W. Costerton, G. G. Geesey, and K. J. Cheng, "How bacteria stick," Scientific American, vol. 238, no. 1, pp. 86-95, 1978.

[18] H. F. Jenkinson and H. M. Lappin-Scott, "Biofilms adhere to stay," Trends in Microbiology, vol. 9, no. 1, pp. 9-10, 2001.

[19] G. Sundqvist, "Taxonomy, ecology, and pathogenicity of the root canal flora," Oral Surgery, Oral Medicine, Oral Pathology, vol. 78, no. 4, pp. 522-530, 1994.

[20] M. Zehnder, "Root canal irrigants," Journal of Endodontics, vol. 32, no. 5, pp. 389-398, 2006.

[21] L. E. Chavez De Paz, G. Dahlen, A. Molander, A. Möller, and G. Bergenholtz, "Bacteria recovered from teeth with apical periodontitis after antimicrobial endodontic treatment," International Endodontic Journal, vol. 36, no. 7, pp. 500-508, 2003.

[22] B. Engstrom, "The significance of Enterococci in root canal treatment," Odontol Revy, vol. 15, pp. 87-106, 1964.

[23] M. Haapasalo, K. Ranta, and H. Ranta, "Facultatice Gramnegative enteric rods in persistent periapical infections," Acta Odontol Scand, vol. 91, pp. 458-463, 1983.

[24] T. M. T. Waltimo, E. K. Siren, H. L. K. Torkko, I. Olsen, and M. P. P. Haapasalo, "Fungi in therapy-resistant apical periodontitis," International Endodontic Journal, vol. 30, no. 2, pp. 96-101, 1997.

[25] L. M. Lin, J. E. Skribner, and P. Gaengler, "Factors associated with endodontic treatment failures," Journal of Endodontics, vol. 18, no. 12, pp. 625-627, 1992.

[26] A. Molander, C. Reit, G. Dahlen, and T. Kvist, "Microbiological status of root-filled teeth with apical periodontitis," International Endodontic Journal, vol. 31, no. 1, pp. 1-7, 1998.

[27] T. D. Becker and G. W. Woollard, "Endodontic irrigation," General Dentistry, vol. 49, no. 3, pp. 272-276, 2001.

[28] K. R. Carson, G. G. Goodell, and S. B. McClanahan, "Comparison of the antimicrobial activity of six irrigants on primary endodontic pathogens," Journal of Endodontics, vol. 31, no. 6, pp. 471-473, 2005.

[29] M. S. Clegg, F. J. Vertucci, C. Walker, M. Belanger, and L. R. Britto, "The effect of exposure to irrigant solutions on apical dentin biofilms in vitro," Journal of Endodontics, vol. 32, no. 5, pp. 434-437, 2006.

[30] R. Garberoglio and C. Becce, "Smear layer removal by root canal irrigants. A comparative scanning electron microscopic study," Oral Surgery, Oral Medicine, Oral Pathology, vol. 78, no. 3, pp. 359-367, 1994.

[31] M. F. Ayad, "Effects of rotary instrumentation and different etchants on removal of smear layer on human dentin," Journal of Prosthetic Dentistry, vol. 85, no. 1, pp. 67-72, 2001.

[32] M. Torabinejad, A. A. Khademi, J. Babagoli et al., "A new solution for the removal of the smear layer," Journal of Endodontics, vol. 29, no. 3, pp. 170-175, 2003.

[33] P. J. Baker, R. T. Evans, R. A. Coburn, and R. J. Genco, "Tetracycline and its derivatives strongly bind to and are released from the tooth surface in active form," Journal of Periodontology, vol. 54, no. 10, pp. 580-585, 1983.

[34] K. Bjorvatn, N. Skaug, and K. A. Selvig, "Tetracycline-impregnated enamel and dentin: duration of antimicrobial capacity," Scandinavian Journal of Dental Research, vol. 93, no. 3, pp. 192-197, 1985.

[35] U. M. Wikesjo, P. J. Baker, and L. A. Christersson, "A biochemical approach to periodontal regeneration: tetracycline treatment conditions dentin surfaces," Journal of Periodontal Research, vol. 21, no. 4, pp. 322-329, 1986.

[36] M. Torabinejad, Y. Cho, A. A. Khademi, L. K. Bakland, and S. Shabahang, "The effect of various concentrations of sodium hypochlorite on the ability of MTAD to remove the smear layer," Journal of Endodontics, vol. 29, no. 4, pp. 233-239, 2003.

[37] R. E. Beltz, M. Torabinejad, and M. Pouresmail, "Quantitative analysis of the solubilizing action of MTAD, sodium hypochlorite, and EDTA on bovine pulp and dentin," Journal of Endodontics, vol. 29, no. 5, pp. 334-337, 2003.

[38] T. K. Machnick, M. Torabinejad, C. A. Munoz, and S. Shabahang, "Effect of MTAD on flexural strength and modulus of elasticity of dentin," Journal of Endodontics, vol. 29, no. 11, pp. 747-750, 2003.

[39] S. Shabahang, M. Pouresmail, and M. Torabinejad, "In vitro antimicrobial efficacy of MTAD and sodium hypochlorite," Journal of Endodontics, vol. 29, no. 7, pp. 450-452, 2003.

[40] S. Shabahang and M. Torabinejad, "Effect of MTAD on Enterococcus faecalis-contaminated root canals of extracted human teeth," Journal of Endodontics, vol. 29, no. 9, pp. 576579, 2003.

[41] M. Torabinejad, S. Shabahang, R. M. Aprecio, and J. D. Kettering, "The antimicrobial effect of MTAD: an in vitro 
investigation," Journal of Endodontics, vol. 29, no. 6, pp. 400403, 2003.

[42] W. Zhang, M. Torabinejad, and Y. Li, "Evaluation of cytotoxicity of MTAD using the MTT-tetrazolium method," Journal of Endodontics, vol. 29, no. 10, pp. 654-657, 2003.

[43] B. M. Newberry, S. Shabahang, N. Johnson, R. M. Aprecio, and M. Torabinejad, "The antimicrobial effect of biopure MTAD on eight strains of enterococcus faecalis: an in vitro investigation," Journal of Endodontics, vol. 33, no. 11, pp. 1352-1354, 2007.

[44] M. Mancini, E. Armellin, A. Casaglia, L. Cerroni, and L. Cianconi, "A comparative study of smear layer removal and erosion in apical intraradicular dentine with three irrigating solutions: a scanning electron microscopy evaluation," Journal of Endodontics, vol. 35, no. 6, pp. 900-903, 2009.

[45] M. E. Vianna, B. P. F. A. Gomes, V. B. Berber, A. A. Zaia, C. C.R. Ferraz, and F. J. de Souza-Filho, "In vitro evaluation of the antimicrobial activity of chlorhexidine and sodium hypochlorite," Oral Surgery, Oral Medicine, Oral Pathology, Oral Radiology, and Endodontics, vol. 97, no. 1, pp. 79-84, 2004.

[46] T. M.T. Waltimo, D. Orstavik, E. K. Sirén, and M. P.P. Haapasalo, "In vitro susceptibility of Candida albicans to four disinfectants and their combinations," International Endodontic Journal, vol. 32, no. 6, pp. 421-429, 1999.

[47] B. H. Sen, B. G. Akdeniz, and A. A. Denizci, "The effect of ethylenediamine-tetraacetic acid on Candida albicans," Oral Surgery, Oral Medicine, Oral Pathology, Oral Radiology, and Endodontics, vol. 90, no. 5, pp. 651-665, 2000.

[48] H. F. Chambers, "Antimicrobial agents: protein synthesis inhibitors and miscellaneous antibacterial agents," in Goodman \& Gilman's The Pharmacological Basis of Therapeutics, J. G. Hardman and L. E. Limbird, Eds., pp. 1240-1246, The McGraw-Hill, New York, NY, USA, 10th edition, 2001.

[49] J. J. Smith and B. E. Wayman, "An evaluation of the antimicrobial effectiveness of citric acid as a root canal irrigant," Journal of Endodontics, vol. 12, no. 2, pp. 54-58, 1986.

[50] A. Zamany, K. Safavi, and L. S.W. Spångberg, "The effect of chlorhexidine as an endodontic disinfectant," Oral Surgery, Oral Medicine, Oral Pathology, Oral Radiology, and Endodontics, vol. 96, no. 5, pp. 578-581, 2003.

[51] M. L. Ruff, S. B. McClanahan, and B. S. Babel, "In vitro antifungal efficacy of four irrigants as a final rinse," Journal of Endodontics, vol. 32, no. 4, pp. 331-333, 2006.

[52] L. Giardino, E. Ambu, C. Becce, L. Rimondini, and M. Morra, "Surface tension comparison of four common root canal irrigants and two new irrigants containing antibiotic," Journal of Endodontics, vol. 32, no. 11, pp. 1091-1093, 2006.

[53] L. Giardino, E. Ambu, E. Savoldi, R. Rimondini, C. Cassanelli, and E. A. Debbia, "Comparative evaluation of antimicrobial efficacy of sodium hypochlorite, MTAD, and Tetraclean against enterococcus faecalis biofilm," Journal of Endodontics, vol. 33, no. 7, pp. 852-855, 2007.

[54] A. M. Solovyeva and P. M. H. Dummer, "Cleaning effectiveness of root canal irrigation with electrochemically activated anolyte and catholyte solutions: a pilot study," International Endodontic Journal, vol. 33, no. 6, pp. 494-504, 2000.

[55] V. M. Bakhir, P. A. Kirpichnikov, and A. G. Liakumovich, "On the nature of electrochemical activation of media," Reports of the USSR Academy of Sciences, vol. 286, pp. 663-666, 1986.

[56] V. M. Bakhir, L. E. Spector, G. ZadorozhnyYu, N. M. Lysenko, and A. RudinskyYa, "A device for electrochemical treatment of liquids," USSR certificate of authorship number 1719316, 1989.

[57] V. I. Prilutskii, V. M. Bakhir, and A. I. Popov, "The disinfection of water, water-supply systems, tanks and pools by using an electrochemically activated solution of a neutral anolyte," Voprosy Kurortologii, Fizioterapii, Lechebnoi FizKultury, no. 4, pp. 31-32, 1996.

[58] J. B. Selkon, J. R. Babb, and R. Morris, "Evaluation of the antimicrobial activity of a new super-oxidized water, Sterilox, for the disinfection of endoscopes." Journal of Hospital Infection, vol. 41, no. 1, pp. 59-70, 1999.

[59] G. Hata, M. Uemura, F. S. Weine, and T. Toda, "Removal of smear layer in the root canal using oxidative potential water," Journal of Endodontics, vol. 22, no. 12, pp. 643-645, 1996.

[60] N. Shetty, S. Srinivasan, J. Holton, and G. L. Ridgway, "Evaluation of microbicidal activity of a new disinfectant: sterilox $®$ 2500 against Clostridium difficile spores, Helicobacter pylori, vancomycin resistant Enterococcus species, Candida albicans and several Mycobacterium species," Journal of Hospital Infection, vol. 41, no. 2, pp. 101-105, 1999.

[61] T. I. Shraev and A. N. Legchilo, "Use of electrochemically activated $0.8 \%$ potassium chloride solutions in the treatment of empyema and parietal abscesses of the lung," Thoracic and Cardiovascular Surgery, no. 4, pp. 64-68, 1989.

[62] T. I. Shraev, A. N. Legchilo, A. T. Kharlamov, and A. A. Legchilo, "Sanitization of bronchial pathways by electrochemically activated solution of $0.8 \%$ potassium chloride," Anesthesiology and Intensive Care, vol. 1, pp. 22-23, 1993.

[63] A. N. Legchilo, A. A. Legchilo, and I. O. Mostovshchikov, "Preparation of suppurative wounds for autodermatoplasty with electrochemically activated solutions," Surgery, vol. 1, pp. 57-58, 1996.

[64] J. C. Baumgartner and C. L. Mader, "A scanning electron microscopic evaluation of four root canal irrigation regimens," Journal of Endodontics, vol. 13, no. 4, pp. 147-157, 1987.

[65] W. T. Broadwater, R. C. Hoehn, and P. H. King, "Sensitivity of three selected bacterial species to ozone," Journal of Applied Microbiology, vol. 26, no. 3, pp. 391-393, 1973.

[66] M. Nagayoshi, C. Kitamura, T. Fukuizumi, T. Nishihara, and M. Terashita, "Antimicrobial effect of ozonated water on bacteria invading dentinal tubules," Journal of Endodontics, vol. 30, no. 11, pp. 778-781, 2004.

[67] N. Z. Ibrahim and M. Abdullah, "Antimicrobial evaluation of sodium hypochlorite and ozonated water on E. faecalis biofilm," Annals of Dentistry, vol. 15, no. 1, pp. 20-26, 2008.

[68] G. Levy, I. Rizoiu, S. Friedman, and H. Lam, "Pressure waves in root canals induced by Nd: YAG laser," Journal of Endodontics, vol. 22, no. 2, pp. 81-84, 1996.

[69] Y. Tomita and A. Shima, "Mechanisms of impulsive pressure generation and damage pit formation by bubble collapse," The Journal of Fluid Mechanics, vol. 169, pp. 535-564, 1986.

[70] A. Baysan and E. Lynch, "The use of ozone in dentistry and medicine," Primary Dental Care, vol. 12, no. 2, pp. 47-52, 2005.

[71] R. Hmud, W. A. Kahler, R. George, and L. J. Walsh, "Cavitational effects in aqueous endodontic irrigants generated by near-infrared lasers," Journal of Endodontics, vol. 36, no. 2, pp. 275-278, 2010.

[72] K. C. Huth, M. Quirling, S. Maier, and K. Kamereck, "Effectiveness of ozone against endodontopathogenic microorganisms in a root canal biofilm model," International Endodontic Journal, vol. 42, pp. 3-13, 2009. 
[73] R. S. Hems, K. Gulabivala, Y. L. Ng, D. Ready, and D. A. Spratt, "An in vitro evaluation of the ability of ozone to kill a strain of Enterococcus faecalis," International Endodontic Journal, vol. 38, no. 1, pp. 22-29, 2005.

[74] C. Estrela, C. R. A. Estrela, D. A. Decurcio, A. C. B. Hollanda, and J. A. Silva, "Antimicrobial efficacy of ozonated water, gaseous ozone, sodium hypochlorite and chlorhexidine in infected human root canals," International Endodontic Journal, vol. 40, no. 2, pp. 85-93, 2007.

[75] C. G. Nogales, P. H. Ferrari, E. O. Kantorovich, and J. LageMarques, "Ozone therapy in medicine and dentistry," Journal of Contemporary Dental Practice, vol. 9, no. 4, pp. 75-84, 2008.

[76] O. Raab, "Uber die Wirkung Fluoreszierender Stoffe auf Infusorien," Zeitschrift für Biologie, vol. 39, pp. 524-546, 1900.

[77] T. J. Dougherty, C. J. Gomer, B. W. Henderson et al., "Photodynamic therapy," Journal of the National Cancer Institute, vol. 90, no. 12, pp. 889-905, 1998.

[78] F. Harris, L. K. Chatfield, and D. A. Phoenix, "Phenothiazinium based photosensitisers-photodynamic agents with a multiplicity of cellular targets and clinical applications," Current Drug Targets, vol. 6, no. 5, pp. 615-627, 2005.

[79] N. S. Soukos, P. S. Y. Chen, J. T. Morris et al., "Photodynamic therapy for endodontic disinfection," Journal of Endodontics, vol. 32, no. 10, pp. 979-984, 2006.

[80] F. Foschi, C. R. Fontana, K. Ruggiero et al., "Photodynamic inactivation of Enterococcus faecalis in dental root canals in vitro," Lasers in Surgery and Medicine, vol. 39, no. 10, pp. 782787, 2007.

[81] S. George and A. Kishen, "Advanced noninvasive light-activated disinfection: assessment of cytotoxicity on fibroblast versus antimicrobial activity against Enterococcus faecalis," Journal of Endodontics, vol. 33, no. 5, pp. 599-602, 2007.

[82] S. George and A. Kishen, "Photophysical, photochemical, and photobiological characterization of methylene blue formulations for light-activated root canal disinfection," Journal of Biomedical Optics, vol. 12, no. 3, Article ID 034029, pp. 2934, 2007.

[83] J. L. Fimple, C. R. Fontana, F. Foschi et al., "Photodynamic treatment of endodontic polymicrobial infection in vitro," Journal of Endodontics, vol. 34, no. 6, pp. 728-734, 2008.

[84] S. George and A. Kishen, "Augmenting the antibiofilm efficacy of advanced noninvasive light activated disinfection with emulsified oxidizer and oxygen carrier," Journal of Endodontics, vol. 34, no. 9, pp. 1119-1123, 2008.

[85] Z. Lim, J. L. Cheng, T. W. Lim et al., "Light activated disinfection: an alternative endodontic disinfection strategy," Australian Dental Journal, vol. 54, no. 2, pp. 108-114, 2009.

[86] N. S. Soukos, S. S. Socransky, S. E. Mulholland, S. Lee, and A. G. Doukas, "Photomechanical drug delivery into bacterial biofilms," Pharmaceutical Research, vol. 17, no. 4, pp. 405409, 2000.

[87] M. A. A. Ogura, A. D. Abernethy, R. D. Blissett et al., "Photomechanical wave-assisted molecular delivery in oral biofilms," World Journal of Microbiology and Biotechnology, vol. 23, no. 11, pp. 1637-1646, 2007.

[88] P. Muller, B. Guggenheim, and P. R. Schmidlin, "Efficacy of gasiform ozone and photodynamic therapy on a multispecies oral biofilm in vitro," European Journal of Oral Sciences, vol. 115, no. 1, pp. 77-80, 2007.

[89] C. R. Fontana, A. D. Abernethy, S. Som et al., "The antibacterial effect of photodynamic therapy in dental plaque-derived biofilms," Journal of Periodontal Research, vol. 44, no. 6, pp. 751-759, 2009.

[90] J. A. Williams, G. J. Pearson, M. J. Colles, and M. Wilson, "The effect of variable energy input from a novel light source on the photoactivated bactericidal action of toluidine blue o on Streptococcus mutans," Caries Research, vol. 37, no. 3, pp. 190-193, 2003.

[91] G. J. Seal, Y. L. Ng, D. Spratt, M. Bhatti, and K. Gulabivala, "An in vitro comparison of the bactericidal efficacy of lethal photosensitization or sodium hyphochlorite irrigation on Streptococcus intermedius biofilms in root canals," International Endodontic Journal, vol. 35, no. 3, pp. 268-274, 2002.

[92] C. S. Leticia, P. R. R. Brito, J. C. Machado de Oliveira et al., "Photodynamic therapy with two different photosensitizers as a supplement to instrumentation/irrigation procedures in promoting intracanal reduction of Enterococcus faecalis," Journal of Endodontics, vol. 36, no. 2, pp. 292-296, 2010.

[93] T. C. Pagonis, J. Chen, C. R. Fontana et al., "Nanoparticlebased Endodontic antimicrobial photodynamic therapy," Journal of Endodontics, vol. 36, no. 2, pp. 322-328, 2010.

[94] P. E. Murray, R. M. Farber, K. N. Namerow, S. Kuttler, and F. Garcia-Godoy, "Evaluation of Morinda citrifolia as an Endodontic Irrigant," Journal of Endodontics, vol. 34, no. 1, pp. 66-70, 2008.

[95] G. C. Jagetia, M. S. Baliga, K. J. Malagi, and M. Sethukumar Kamath, "The evaluation of the radioprotective effect of triphala (an ayurvedic rejuvenating drug) in the mice exposed to $\gamma$-radiation," Phytomedicine, vol. 9, no. 2, pp. 99108, 2002.

[96] J. M. T. Hamilton-Miller, "Anti-cariogenic properties of tea (Camellia sinensis)," Journal of Medical Microbiology, vol. 50, no. 4, pp. 299-302, 2001.

[97] J. Prabhakar, M. Senthilkumar, M. S. Priya, K. Mahalakshmi, P. K. Sehgal, and V. G. Sukumaran, "Evaluation of antimicrobial efficacy of herbal alternatives (Triphala and green tea Polyphenols), MTAD, and 5\% sodium hypochlorite against Enterococcus faecalis biofilm formed on tooth substrate: an in vitro study," Journal of Endodontics, vol. 36, no. 1, pp. 8386, 2010.

[98] S. W. Jacob and R. Herschler, "Biological actions of dimethyl sulfoxide," Annals of the New York Academy of Sciences, vol. 243, pp. 1-508, 1975.

[99] J. C. de la Torre, "Biological actions and medical applications of dimethyl sulfoxide," Annals of the New York Academy of Sciences, vol. 411, pp. 1-403, 1983.

[100] T. Vani, M. Rajani, S. Sarkar, and C. J. Shishoo, "Antioxidant properties of the ayurvedic formulation triphala and its constituents," International Journal of Pharmacognosy, vol. 35, no. 5, pp. 313-317, 1997.

[101] M. Rasool and E. P. Sabina, "Antiinflammatory effect of the Indian ayurvedic herbal formulation Triphala on adjuvantinduced arthritis in mice," Phytotherapy Research, vol. 21, no. 9, pp. 889-894, 2007.

[102] G. C. Jagetia, K. J. Malagi, M. S. Baliga, P. Venkatesh, and R. R. Veruva, "Triphala, an ayurvedic rasayana drug, protects mice against radiation-induced lethality by free-radical scavenging," Journal of Alternative and Complementary Medicine, vol. 10, no. 6, pp. 971-978, 2004.

[103] B. Zhao, "Antioxidant effects of green tea polyphenols," Chinese Science Bulletin, vol. 48, no. 4, pp. 315-319, 2003. 


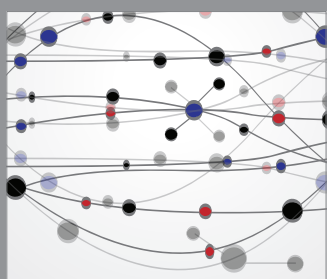

The Scientific World Journal
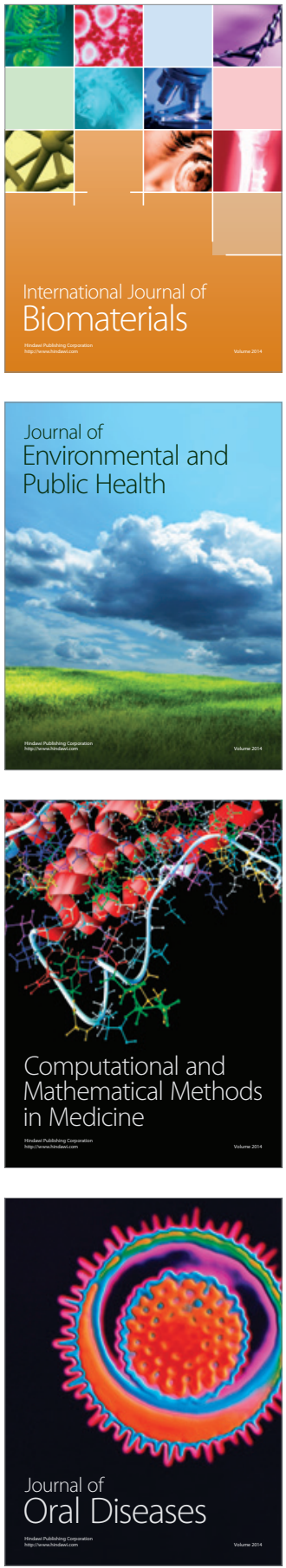
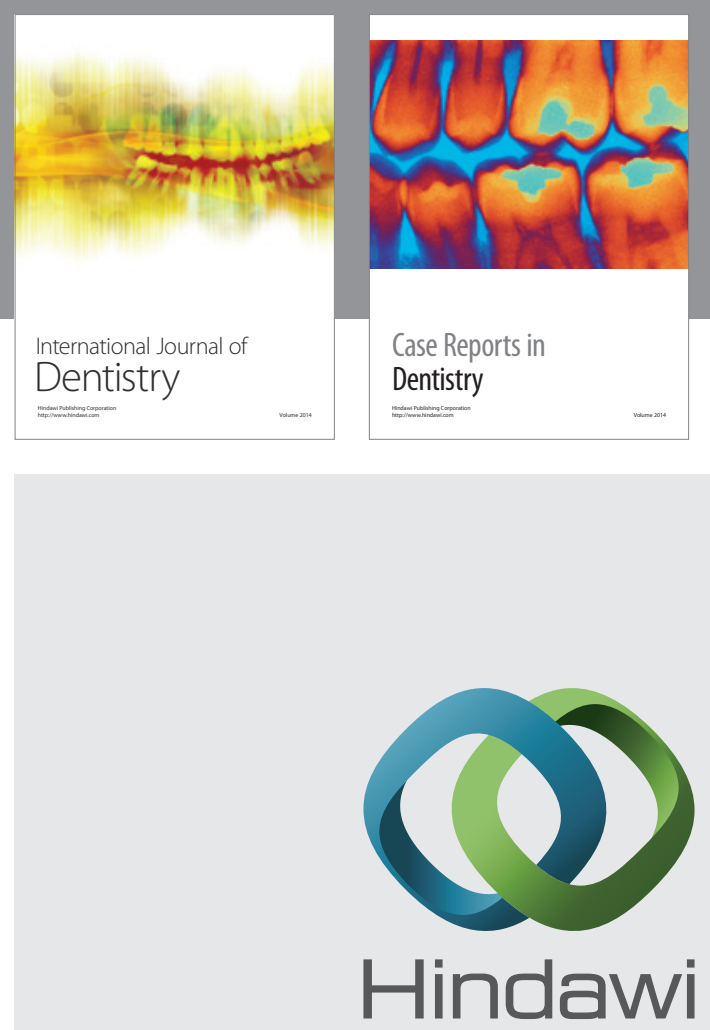

Submit your manuscripts at

http://www.hindawi.com
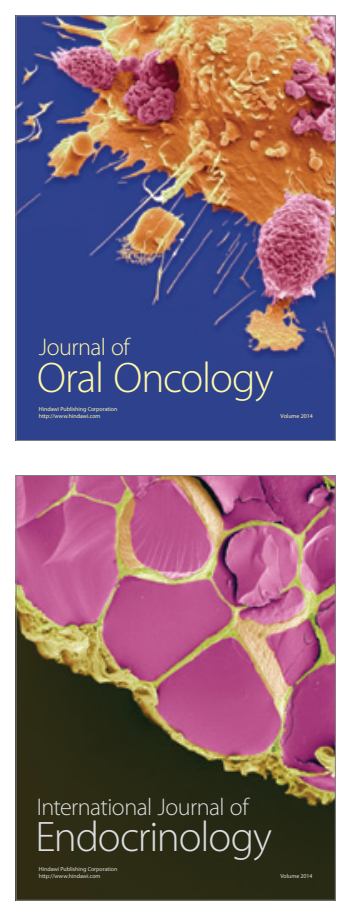
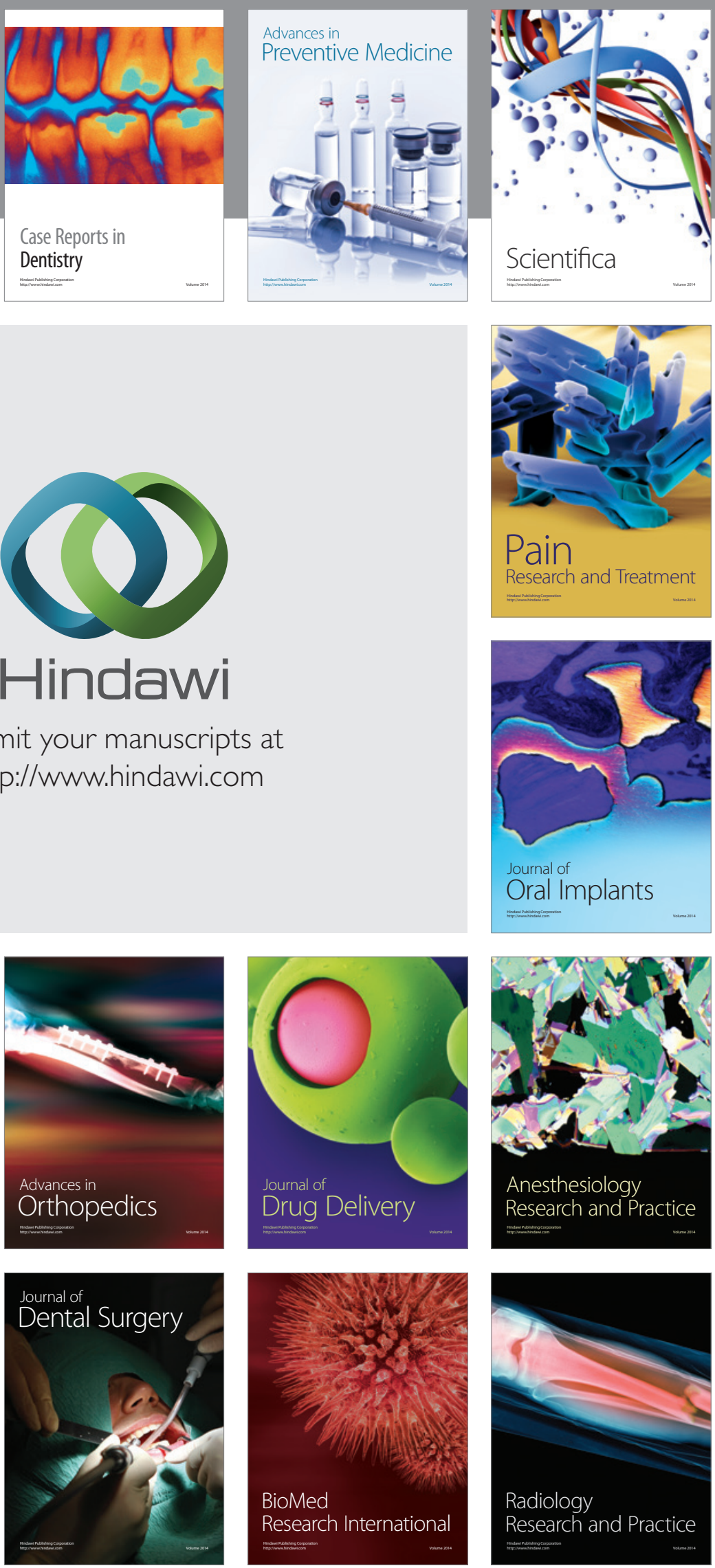